\title{
Moral injury and Light Triad traits: anxiety and depression in health-care personnel during the COVID-19 pandemic
}

\author{
Elizabeth Andino Rodríguez ${ }^{1}$, Maitée Agüero-Flores ${ }^{1}$, Miguel Landa-Blanco $^{1}$, David \\ Gerardo Agurcia $^{2} \&$ Cindy Santos-Midence ${ }^{2}$
}

\begin{abstract}
During the COVID-19 pandemic, health workers are facing morally challenging, stressful, and life-threatening decisions while working with limited human and medical resources. The purpose of the current study was to determine the influence of Moral Injury and Light Triad (LT) personality traits on anxiety and depression symptoms of health-care personnel during the COVID-19 pandemic. A quantitative, cross-sectional research design was used, the study included a sample of 169 health-care workers. Data was gathered through the Moral Injury Symptom Scale for Health Professionals (MISSHP), Light Triad Scale (LTS), the Generalized Anxiety Disorder- 7 (GAD-7), and the Patient-Health Questionnaire-9 (PHQ-9). Results suggest that almost 9 out of 10 respondents experienced at least one potentially morally injurious event, $45.6 \%$ were at significant risk of impairment related to Moral Injury. Working with limited staff and resources, and the implications of it, were among the most common potentially morally injurious situations reported by the respondents. Results suggest that MISS-HP Mistrust subscale has significant negative correlations with Light Triad traits. A hierarchical regression model determined that Moral Injury, but not Light Triad traits, significantly affected depression symptoms. The overall model accounted for $42.6 \%$ of the variance in depression scores. On the other hand, anxiety symptoms were significantly predicted by Moral Injury, as did LTS-Humanism. The model accounted for $38.2 \%$ of the variance in anxiety scores. Control variables included respondents' sex, years of experience, profession, and prior COVID-19 diagnosis. The results were discussed according to their implications to public health.
\end{abstract}

Keywords: Moral Injury, Light Triad, anxiety, depression, COVID-19, healthcare workers

${ }^{1}$ Affiliated to the master's degree in Clinical Psychology, School of Psychological Sciences of the National Autonomous University of Honduras (UNAH).

${ }^{2}$ Independent researchers, Tegucigalpa, Honduras.

Correspondence concerning this article should be addressed to Elizabeth Andino Rodríguez, email: elizabeth.andino@unah.hn 


\section{Introduction}

The study of Moral Injury has gained visibility on the literature related to psychological trauma, however, studies on the topic typically focus on war veterans (Currier, Holland, $\&$ Malott, 2015). Even though health-care personnel are at particular risk of suffering moral injuries during the COVID-19 pandemic (Williamson, Murphy, \& Greenberg, 2020), there are still important gaps in the literature on the topic in such professional population (Mantri, Lawson, Wang, \& Koenig, 2020).

The term Moral Injury refers to experiences of stress and impairment lived by individuals who have been exposed to traumatic events in which acts contrary to personal moral principles are committed (Griffin et al., 2019). Situations in which a person commits, or fails to prevent, an act against their moral beliefs may result in Moral Injury. Being witness to such events, even when committed by others, may also lead to Moral Injury (Litz et al., 2009). The risk of Moral Injury increases when the aversive situation involves a detriment in the well-being of vulnerable populations. Other conditions that increase the risk of Moral Injury include the lack of interpersonal support, feelings of psychological unpreparedness to face the consequences of certain actions, and perceiving leaders as unsupportive or irresponsible (Williamson et al., 2020).

It is worth mentioning that Moral Injury itself is not a mental illness, nonetheless, people experimenting it can develop symptoms (such as shame, guilt or disgust), which may result in a deterioration of mental health (Greenberg, Docherty, Gnanapragasam, \& Wessely, 2020). People experiencing Moral Injury may have self-blaming, and selfpunishment behaviors, increased suicidality and anguish, as well as a deterioration in self-confidence and their willingness to trust others (Molendijk, 2018; Shay, 2014).

Health-care providers are often forced to make decisions inconsistent with personal values or with limited clinical resources, this is considered a significant source of stress, guilt, and shame. In addition, due to limitations in health systems, there are often circumstances in which some patients have access to certain treatments, while others are excluded from such cares (Haller et al., 2020; Williams, Brundage, \& Williams, 2020). This is a particular risk to health systems with limited resources that have been overwhelmed by the COVID-19 pandemic, such is the case in the Latin-American region (Litewka \& Heitman, 2020).

Another source of guilt during the COVID-19 pandemic relates to the infection of others, in which health-care personnel may carry the virus to their loved ones, risking their lives. This guilt may be maximized when such events result in the death of loved ones, due to COVID-19. In such cases, the person may feel overly responsible for the situation (Cavalera, 2020). Additionally, there might be Moral Injury related to the constant responsibility of giving bad news to patients or their families (Greenberg et al., 2020).

Anxiety is a state of psychophysiological agitation and vigilance, it is usually accompanied by muscle tension and avoidant behaviors. Anxiety is often detonated by the anticipation of future events that are perceived as aversive or dangerous. High levels of anxiety may result in cognitive and behavioral dysfunction (American Psychiatric 
Association, 2013). On the other hand, depression is usually characterized by an increased psychological and physical dysfunction associated with feelings of sadness, hopelessness, emptiness, irritability, changes in sleep patterns, changes in weight, diminished concentration capability, anomia, abulia and either psychomotor retardation or agitation (American Psychiatric Association, 2013).

When compared to the general population, health-care workers are at particular risk of suffering mood and anxiety disorders (Kim et al., 2018), even more so during the COVID-19 pandemic (Hacimusalar, Kahve, Yasar, \& Aydin, 2020). Health-care workers who are on the frontline to fight the COVID-19 pandemic are constantly exposed to stressful situations with extended working hours, this could adversely impact both on their mental and physical health. A recent study made during this crisis, reported that $38 \%$ of the participants suffered mild anxiety, $20 \%$ moderate anxiety and $13 \%$ severe anxiety (Korkmaz et al., 2020). A different study made among New York health-care staff found that $57 \%$ reported acute stress, $48 \%$ depressive symptoms and $33 \%$ anxiety symptoms (Shechter et al., 2020). Additionally, studies made in health personnel during the COVID-19 pandemic have found significant relationships between Moral Injury and depression, anxiety, emotional exhaustion and depersonalization (Zhizhong et al., 2020).

The Light Triad (LT) of personality consists of traits related to love and beneficent towards others, it includes three main dimensions. The first is Kantianism, which consists of treating others as ends unto themselves. Humanism describes the value given to people in terms of their implicit dignity and worth. Finally, believing that people are essentially good is categorized under the Faith in Humanity trait. LT correlates positively with compassion, politeness, sincerity, fairness, respectfulness, empathy, benevolence, kindness, and interpersonal guilt. On the other hand it correlated negatively with anxiety and depression (Kaufman, Yaden, Hyde, \& Tsukayama, 2019), as such LT is deemed as a relevant topic for the current study.

Given the importance of Moral Injury in the psychological well-being of health-care workers during the COVID-19 pandemic (Cheng \& Li Ping Wah-Pun Sin, 2020), as well as the gaps in literature on such topic (Mantri et al., 2020), the purpose of the current study was to identify how anxiety and depression symptoms are affected by Light Triad traits and Moral Injury in a sample of health-care workers during the COVID-19 pandemic in Honduras.

\section{Materials and methods}

\section{Participants}

The sample size was 169 health-care professionals from Honduras, a volunteersnowball sampling method was used to collect data. Due to COVID-19 risks and limitations, all data was collected online. On average, respondents had an age of 36.04 years $(S D=10.46)$ and 8.84 years $(S D=10.51)$ of professional experience as health-care workers. Most respondents were physicians ( $n=146,86.39 \%)$, with nurses accounting for $13.61 \%$ of the sample ( $n=23)$. Most of the participants were female $(n=129,76.33 \%)$ and worked in public hospitals $(n=64,37.87 \%)$. Almost 1 in 3 respondents had been 
previously diagnosed with COVID-19 $(n=50,29.59 \%)$. Table 1 provides a characterization of the sample.

[See Table 1]

\section{Data collection techniques}

\section{Moral Injury}

Data was collected through the Moral Injury Symptom Scale for Health Professionals (MISS-HP). The instrument consists of 10 items, each of them rated from 1 to 10, with overall scores ranging from 10 to 100 . Higher scores indicate a higher prevalence of Moral Injury symptoms. The MISS-HP includes an additional question about the selfperceived dysfunctionality caused by Moral Injury. Moreover, scores equal or greater than 36 suggest significant risk of impairment in the social, professional or familiar domains (Mantri et al., 2020). Three dimensions build the MISS-HP: Shame and Guilt, Mistrust, and Lack of Forgiveness (Zhizhong et al., 2020). In the current study the MISS-HP had an adequate internal consistency, $\alpha=0.76,95 \%$ CI $[0.70,0.81]$.

Additional information regarding Moral Injury in the health-care setting was collected through a checklist containing nine examples of situations that can detonate Moral Injury in health-care providers (Greenberg et al., 2020). Such situations include following unethical or dubious clinical instructions, feeling upset by the lack of resources available at work, not reporting clinical incidents, etc. Participants could select none or many of the presented options.

\section{Light Triad Scale (LTS)}

The Light Triad Scale (LTS) is a 12-item, 5-point Likert type questionnaire that measures Kantianism, Humanism and Faith in Humanity. The LTS has demonstrated to be a valid and reliable instrument (Kaufman et al., 2019). In the current study, the LTS achieved adequate levels of internal consistency, $\alpha=0.79,95 \%$ CI [0.74, 0.83].

\section{Patient-Health Questionnaire-9}

Depression symptoms were assessed through the Patient-Health Questionnaire-9 (PHQ9), a nine-item instrument with a four-point Likert-type scale, with item scores ranging from 0 to 3 points. Previous research has determined the PHQ-9 as a valid and reliable screening tool for depressive symptoms (Kroenke, Spitzer, \& Williams, 2001). The current study confirmed the internal reliability of the PHQ-9, $\alpha=0.90,95 \%$ CI $[0.87$, 0.92].

\section{Generalized Anxiety Disorder- 7}

Data regarding anxiety symptoms was collected through the Generalized Anxiety

Disorder- 7 (GAD-7). It includes seven items, with a four-point Likert-type response 
set. Previous research has established the GAD-7 as a valid and reliable measure of anxiety symptoms (Spitzer, Kroenke, Williams, \& Löwe, 2006). With the current data, the GAD-7 achieved adequate levels of internal consistency, $\alpha=0.93,95 \%$ CI [0.82, $0.95]$.

\section{Demographic and work-related experience questionnaire}

Respondents were asked to report general demographic and work-related information through a questionnaire. These included: sex, age, years of experience as a health-care worker, profession, workplace, and having a prior COVID-19 diagnosis.

\section{Ethical considerations}

The research was conducted in accordance with the Helsinki Declaration as revised in 1989. Additionally, the current study was approved and made in accordance with the Ethical Guidelines required by the master's degree in Clinical Psychology, of the School of Psychological Sciences of the National Autonomous University of Honduras. All participants were presented with an informed consent form which detailed the purpose of the study, a participation statement (including data management, anonymity, actions required by the participant, voluntary agreement, etc.), and contact information for the main researcher.

\section{Data analysis}

First, summative scores were obtained for each Likert-type questionnaire included in the study. Later, a descriptive analysis was made, including frequencies, percentages, means, and standard deviations. Two group comparisons were made using Student's $t$ test, results were complemented with effect size calculations through Cohen's $d$. The relationship between LTS and MISS-HP was assessed through Pearson's $r$. Finally, a hierarchical regression was made to quantify how depression and anxiety symptoms were explained by Moral Injury and Light Triad Traits, while controlling for respondents' sex, profession, prior COVID-19 diagnosis, and years of experience. Control variables were introduced in Model 1, all variables were included in Model 2. The effect size for the regression models $\left(f^{2}\right)$ and post-hoc achieved power were calculated using G*Power (Faul, Erdfelder, Buchner, \& Lang, 2009).

\section{Results}

\section{Descriptive statistics for Moral Injury in health-care personnel}

A frequency analysis regarding the prevalence of the potential morally injurious events for health-care professionals was made. Results suggest that most of the respondents (74.60\%) reported to feel upset by being forced to work with limited staff or resources, 
$46.70 \%$ of the respondents reported "returning home from a shift and hearing of seriously worsening outcomes in your work facility", and $26.60 \%$ had followed clinical decisions that were dimmed unethical or not supported by scientific guidance. Of the total sample size, 16 respondents $(9.50 \%)$ had not experienced any of the enlisted potential moral injurious events, see Table 2.

[See Table 2]

When asked about the degree of stress or impairment caused by the situations described in Table 3, 22.5\% $(n=38)$ responded "not at all", 43.8\% $(n=74)$ "mild", $28.4 \%(n=48)$, $4.1 \%(n=7)$ "very much" and 1.2\% $(n=2)$ "extremely". However, Mantri et al. (2020) suggest that MISS-HP scores above 36 tend to indicate significant impairment in family, social and professional functioning. By this standard, $45.6 \%(n=77)$ of the sample had scores equal or higher than 36 points on the MISS-HP, indicating significant risk of impairment. Respondent's with MISS-HP scores of 36 or more reported statistically higher levels of depression symptoms $(p<0.001, d=-1.11)$ and anxiety symptoms $(p<0.001, d=-1.06)$ than people with lower scores, see Table 4.

[See Table 3]

[See Table 4]

\section{Relationship between Moral Injury and Light Triad traits}

Results suggest that MISS-HP Mistrust has significant negative correlations with LTFaith in Humanity, LT-Humanism and LT-Kantianism. On the other hand, MISS-HP Lack of Forgiveness correlates negatively with LT-Faith in Humanity. Other correlations between Light Triad Traits and Moral Injury are presented in Table 5.

[See Table 5]

\section{Moral Injury and Light Triad traits as predictors of depression symptoms}

A hierarchical regression was made to quantify how depression symptoms were explained by Moral Injury and Light Triad traits, while controlling for respondents' sex, profession, prior COVID-19 diagnosis, and years of experience. Control variables were introduced in Model 1, all variables were included in Model 2. Results indicate that Model 1 was not statistically significant, $F(4,164)=1.86, p=0.119, r^{2}=0.044$. On the other hand, Model 2 showed a significant improvement in $r^{2}(0.426)$ when compared to the base model, $p<0.01$; the ANOVA test also resulted significant, $F(10,158)=11.732$, $p<0.01$. The achieved effect size $\left(f^{2}\right)$ of the regression model was of 0.74 , an effect size classified as "large" (Cohen, 1992), with a high power (>0.99). All the subscales of the MISS-HP significantly explained PHQ-9 scores $(p<0.01)$. Neither control variables, nor Light Triad traits had significant effects over PHQ-9 scores, see Table 6. 
[See Table 6]

\section{Moral Injury and Light Triad traits as predictors of anxiety symptoms}

Additionally, a similar regression analysis was used to explain anxiety symptoms. Results indicate that Model 1 was statistically significant, $F(4,164)=2.465, p=0.047$, $r^{2}=0.057$. However, Model 2 showed a significant improvement in $r^{2}(0.382)$ when compared to the base model, $p<0.01$; the ANOVA test also resulted significant, $F(10$, $158)=9.782 p<0.01$. The achieved effect size $\left(f^{2}\right)$ of the regression model was of 0.61 , an effect size classified as "large" (Cohen, 1992), with a high power $(>0.99)$. All the subscales of the MISS-HP significantly explained GAD-7 scores as did LT-Humanism $(p<0.01)$. No other variables had significant effects, $p>0.05$, see Table 7 .

[See Table 7]

\section{Discussion}

The results of the current research suggest that a relevant percentage of health-care personnel consider that they are working with limited staff and resources. Health-care workers have been forced during this crisis to work during long hours under very stressful situations. This constant exposure to stress can have negative effects on their cognitive and psychomotor functions. Even more so, our findings indicate that $45.6 \%$ of the sample had high scores on the MISS-HP, indicating significant risk of impairment in the social, personal and professional domains of life (Mantri et al., 2020). This cognitive and psychomotor impairment can lead health-care workers to commit medical errors, low involvement in decision-making, low job-satisfaction, absenteeism, and decreased workplace productivity. This not only affects their working life but also their personal life, leading health-care staff to have dysfunctional relationships with their friends and relatives, being involved in vehicle crashes, suffering chronic pain, and fatigue (Weaver et al., 2018). Results of our study provide further evidence that Moral Injury significantly affects depression and anxiety in health-care personnel. Such results are similar to those found in a sample of Chinese nurses and physicians, in which Moral Injury correlated positively with depression and anxiety, while being inversely associated with well-being (Zhizhong et al., 2020).

Although Light Triad traits are typically considered a protective mental health factor (Kaufman et al., 2019), the current study found no evidence of a relationship between such traits and anxiety or depression. That is, except for a positive link between Humanism and anxiety. Given that people with higher levels of Humanism tend to value others according to their implicit dignity (Kaufman et al., 2019), as such, it is possible that the constant worry health-care workers feel about their patients well-being might lead to a compassion fatigue. Such situations may cause emotional impairment and difficulties managing a work-life balance, as has been a common event among health-care workers during the current pandemic (Gold, 2020).

Given the relevance of these findings, all hospitals and clinics should have mental health screening programs that also provide adequate care to prevent and treat mental 
well-being, not only during the pandemic but permanently. Specifically, environments that promote social support among colleagues could enhance resilience in health-care personnel (De Brier, Stroobants, Vandekerckhove, \& De Buck, 2020). This is of particular importance given the role that lack of trust and betrayal play as key domains of Moral Injury (Greenberg et al., 2020; Zhizhong et al., 2020). Additionally, healthcare organizations should promote staff participation in the institutional decisionmaking process. In this sense, a transparent and bidirectional communication between health-care workers and leaders is vital to promote openness and feelings of support (Young et al., 2020).

Future research should investigate the relationship between Moral Injury and PostTraumatic Stress Disorder in health-care workers during the COVID-19 pandemic. Further studies would benefit from considering the relationship between locus of control, burnout, resilience, psychological well-being, and Moral Injury. Finally, to better understand the dynamic between Moral Injury and mental health during the COVID-19 pandemic, prospective studies should use qualitative approaches that explore the subjective constructions of health-care workers regarding their professional experience.

Although the current study offers a valuable insight into the health-care workers mental health, there are limitations worth mentioning. Some of the challenges that emerged throughout the study were the availability and access to the sample. Due to the current COVID-19 pandemic, health-care professionals have limited time to respond to surveys. This might have restricted the willingness of potential respondents to participate in the study. Furthermore, the non-probabilistic sampling approach may limit the inferential capabilities of our results.

\section{Declaration of Competing Interest.}

The authors declare that they have no known competing financial interests or personal relationships that could have appeared to influence the work reported in this paper.

\section{Data Availability Statement}

The data that support the findings of this study are available from the corresponding author, EAR, upon reasonable request. 


\section{References}

American Psychiatric Association. (2013). Diagnostic and statistical manual of mental disorders (5th ed.). Arlington, VA. doi: 10.1176/appi.books.9780890425596

Cavalera, C. (2020). COVID-19 Psychological Implications: The Role of Shame and Guilt. Frontiers in Psychology, 11. doi: 10.3389/fpsyg.2020.571828

Cheng, J. O. S., \& Li Ping Wah-Pun Sin, E. (2020). The effects of nonconventional palliative and end-of-life care during COVID-19 pandemic on mental healthJunior doctors' perspective. Psychological Trauma: Theory, Research, Practice, and Policy, 12(S1), S146-S147. doi: 10.1037/tra0000628

Cohen, J. (1992). A power primer. Psychological Bulletin, 112(1), 155-159. doi: 10.1037/0033-2909.112.1.155

Currier, J. M., Holland, J. M., \& Malott, J. (2015). Moral Injury, Meaning Making, and Mental Health in Returning Veterans. Journal of Clinical Psychology, 71(3), 229240. doi: $10.1002 /$ jclp.22134

De Brier, N., Stroobants, S., Vandekerckhove, P., \& De Buck, E. (2020). Factors affecting mental health of health care workers during coronavirus disease outbreaks (SARS, MERS \& COVID-19): A rapid systematic review. PLOS ONE, 15(12). doi: 10.1371/journal.pone.0244052

Faul, F., Erdfelder, E., Buchner, A., \& Lang, A.-G. (2009). Statistical power analyses using G*Power 3.1: Tests for correlation and regression analyses. Behavior Research Methods, 41(4), 1149-1160. doi: 10.3758/BRM.41.4.1149

Gold, J. A. (2020). Covid-19: adverse mental health outcomes for healthcare workers. BMJ, 369, m1815. doi: 10.1136/bmj.m1815

Greenberg, N., Docherty, M., Gnanapragasam, S., \& Wessely, S. (2020). Managing mental health challenges faced by healthcare workers during covid-19 pandemic. BMJ, 368, m1211. doi: 10.1136/bmj.m1211

Griffin, B. J., Purcell, N., Burkman, K., Litz, B. T., Bryan, C. J., Schmitz, M., ... Maguen, S. (2019). Moral Injury: An Integrative Review. Journal of Traumatic Stress, 32(3), 350-362. doi: 10.1002/jts.22362

Hacimusalar, Y., Kahve, A. C., Yasar, A. B., \& Aydin, M. S. (2020). Anxiety and hopelessness levels in COVID-19 pandemic: A comparative study of healthcare professionals and other community sample in Turkey. Journal of Psychiatric Research, 129, 181-188. doi: 10.1016/j.jpsychires.2020.07.024

Haller, M., Norman, S. B., Davis, B. C., Capone, C., Browne, K., \& Allard, C. B. (2020). A model for treating COVID-19-related guilt, shame, and moral injury. Psychological Trauma: Theory, Research, Practice, and Policy, 12(S1), S174S176. doi: $10.1037 / \operatorname{tra} 0000742$

Kaufman, S. B., Yaden, D. B., Hyde, E., \& Tsukayama, E. (2019). The Light vs. Dark Triad of Personality: Contrasting Two Very Different Profiles of Human Nature. Frontiers in Psychology, 10, 467. doi: 10.3389/fpsyg.2019.00467

Kim, M.-S., Kim, T., Lee, D., Yook, J., Hong, Y.-C., Lee, S.-Y., ... Kang, M.-Y. (2018). Mental disorders among workers in the healthcare industry: 2014 national 
health insurance data. Annals of Occupational and Environmental Medicine, 30(1). doi: 10.1186/s40557-018-0244-x

Korkmaz, S., Kazgan, A., Çekiç, S., Tartar, A. S., Balcı, H. N., \& Atmaca, M. (2020). The anxiety levels, quality of sleep and life and problem-solving skills in healthcare workers employed in COVID-19 services. Journal of Clinical Neuroscience, 80, 131-136. doi: 10.1016/j.jocn.2020.07.073

Kroenke, K., Spitzer, R. L., \& Williams, J. B. W. (2001). The PHQ-9: Validity of a brief depression severity measure. Journal of General Internal Medicine, 16(9), 606-613. doi: 10.1046/j.1525-1497.2001.016009606.x

Litewka, S. G., \& Heitman, E. (2020). Latin American healthcare systems in times of pandemic. Developing World Bioethics, 20(2), 69-73. doi: 10.1111/dewb.12262

Litz, B. T., Stein, N., Delaney, E., Lebowitz, L., Nash, W. P., Silva, C., \& Maguen, S. (2009). Moral injury and moral repair in war veterans: A preliminary model and intervention strategy. Clinical Psychology Review, 29(8), 695-706. doi: 10.1016/j.cpr.2009.07.003

Mantri, S., Lawson, J. M., Wang, Z., \& Koenig, H. G. (2020). Identifying Moral Injury in Healthcare Professionals: The Moral Injury Symptom Scale-HP. Journal of Religion and Health, 59(5), 2323-2340. doi: 10.1007/s10943-020-01065-w

Molendijk, T. (2018). Toward an interdisciplinary conceptualization of moral injury: From unequivocal guilt and anger to moral conflict and disorientation. New Ideas in Psychology, 51, 1-8. doi: 10.1016/j.newideapsych.2018.04.006

Shay, J. (2014). Moral injury. Psychoanalytic Psychology, 31(2), 182-191. doi: $10.1037 / \mathrm{a} 0036090$

Shechter, A., Diaz, F., Moise, N., Anstey, D. E., Ye, S., Agarwal, S., ... Abdalla, M. (2020). Psychological distress, coping behaviors, and preferences for support among New York healthcare workers during the COVID-19 pandemic. General Hospital Psychiatry, 66, 1-8. doi: https://doi.org/10.1016/j.genhosppsych.2020.06.007

Spitzer, R. L., Kroenke, K., Williams, J. B. W., \& Löwe, B. (2006). A Brief Measure for Assessing Generalized Anxiety Disorder: The GAD-7. Archives of Internal Medicine, 166(10), 1092-1097. doi: 10.1001/archinte.166.10.1092

Weaver, M. D., Vetter, C., Rajaratnam, S. M. W., O’Brien, C. S., Qadri, S., Benca, R. M., ... Barger, L. K. (2018). Sleep disorders, depression and anxiety are associated with adverse safety outcomes in healthcare workers: A prospective cohort study. Journal of Sleep Research, 27(6), e12722. doi: 10.1111/jsr.12722

Williams, R. D., Brundage, J. A., \& Williams, E. B. (2020). Moral Injury in Times of COVID-19. Journal of Health Service Psychology, 46(2), 65-69. doi: 10.1007/s42843-020-00011-4

Williamson, V., Murphy, D., \& Greenberg, N. (2020). COVID-19 and experiences of moral injury in front-line key workers. Occupational Medicine, 70(5), 317-319. doi: $10.1093 /$ occmed/kqaa052

Young, K. P., Kolcz, D. L., O’Sullivan, D. M., Ferrand, J., Fried, J., \& Robinson, K. (2020). Health Care Workers' Mental Health and Quality of Life During COVID- 
19: Results From a Mid-Pandemic, National Survey. Psychiatric Services, 72(2), 122-128. doi: 10.1176/appi.ps.202000424

Zhizhong, W., Koenig, H. G., Yan, T., Jing, W., Mu, S., Hongyu, L., \& Guangtian, L. (2020). Psychometric properties of the moral injury symptom scale among Chinese health professionals during the COVID-19 pandemic. BMC Psychiatry, 20(1), 556. doi: $10.1186 / \mathrm{s} 12888-020-02954-\mathrm{w}$ 
Table 1

Characterization of the participants

\begin{tabular}{lcc}
\hline Variable & $n$ & $\%$ \\
\hline Sex & & \\
$\quad$ Male & 40 & $23.67 \%$ \\
$\quad$ Female & 129 & $76.33 \%$ \\
Profession & & \\
$\quad$ Physician & 146 & $86.39 \%$ \\
$\quad$ Nurse & 23 & $13.61 \%$ \\
Workplace & & \\
$\quad$ Public hospital & 64 & $37.87 \%$ \\
$\quad$ Health center & 29 & $17.16 \%$ \\
$\quad$ Triage station & 28 & $16.57 \%$ \\
$\quad$ Private consultant & 15 & $8.88 \%$ \\
$\quad$ Private hospital & 13 & $7.69 \%$ \\
COVID-19 brigade & 8 & $4.73 \%$ \\
$\quad$ Other & 12 & $7.10 \%$ \\
Prior COVID-19 & & \\
diagnosis & & \\
$\quad$ Yes & 50 & $29.59 \%$ \\
$\quad$ No & 119 & $70.41 \%$ \\
\hline Note. The total sample size was 169 health-care workers.
\end{tabular}


Table 2

Prevalence of potential morally injurious events in health-care professionals

\begin{tabular}{|c|c|c|c|}
\hline $\begin{array}{l}\text { Potential morally injurious events for health-care } \\
\text { professionals }\end{array}$ & $n$ & $\begin{array}{c}\% \text { of } \\
\text { response } \\
\text { s }\end{array}$ & $\begin{array}{l}\% \text { of } \\
\text { cases }\end{array}$ \\
\hline $\begin{array}{l}\text { Feeling upset because you are working with limited } \\
\text { resources or staff, while perceiving this as avoidable. }\end{array}$ & 126 & $34.90 \%$ & $74.60 \%$ \\
\hline $\begin{array}{l}\text { Returning home from a shift and hearing of seriously } \\
\text { worsening outcomes in your work facility. }\end{array}$ & 79 & $21.90 \%$ & $46.70 \%$ \\
\hline $\begin{array}{l}\text { Following clinical decisions by others that were } \\
\text { unethical, immoral, or against guidance from registered } \\
\text { professionals. }\end{array}$ & 45 & $12.50 \%$ & $26.60 \%$ \\
\hline $\begin{array}{l}\text { Having to choose between two equally sick patients, one } \\
\text { is provided with specific care and the other one doesn't } \\
\text { survive. }\end{array}$ & 27 & $7.50 \%$ & $16.00 \%$ \\
\hline $\begin{array}{l}\text { Change in belief about the justification for treatment } \\
\text { plans that have affected people's lives. }\end{array}$ & 24 & $6.60 \%$ & $14.20 \%$ \\
\hline $\begin{array}{l}\text { Failing to report serious clinical incidents, misses, or } \\
\text { bullying of yourself, colleagues, or patients. }\end{array}$ & 16 & $4.40 \%$ & $9.50 \%$ \\
\hline $\begin{array}{l}\text { Putting patients/colleagues in danger because of your } \\
\text { inexperience, indecision, or working outside your } \\
\text { competency. }\end{array}$ & 12 & $3.30 \%$ & $7.10 \%$ \\
\hline $\begin{array}{l}\text { Responding acutely in a medical emergency and causing } \\
\text { the harm/death of patients, knowingly, but } \\
\text { unintentionally. }\end{array}$ & 10 & $2.80 \%$ & $5.90 \%$ \\
\hline $\begin{array}{l}\text { Giving clinical orders or establishing protocols that } \\
\text { result in the death of colleagues or patients. }\end{array}$ & 6 & $1.70 \%$ & $3.60 \%$ \\
\hline None & 16 & $4.40 \%$ & $9.50 \%$ \\
\hline
\end{tabular}


Table 3

Description of items and factors of the MISS-HP

\begin{tabular}{|c|c|c|}
\hline Items & $M$ & $S D$ \\
\hline Factor: Shame and guilt & 11.73 & 8.16 \\
\hline $\begin{array}{l}\text { 2. I feel guilt over failing to save someone from being seriously injured } \\
\text { or dying. }\end{array}$ & 4.34 & 3.31 \\
\hline 3. I feel ashamed about what I've done or not done when providing care & & \\
\hline to my patients. & 3.59 & 2.95 \\
\hline $\begin{array}{l}\text { 4. I am troubled by having acted in ways that violated my own morals } \\
\text { or values. }\end{array}$ & 3.80 & 3.36 \\
\hline Factor: Mistrust & 10.62 & 5.92 \\
\hline $\begin{array}{l}\text { 5. Most people with whom I work as a health professional are } \\
\text { trustworthy. (R) }\end{array}$ & 6.29 & 2.81 \\
\hline $\begin{array}{l}\text { 6. I have a good sense of what makes my life meaningful as a health } \\
\text { professional. (R) }\end{array}$ & 8.48 & 2.18 \\
\hline $\begin{array}{l}\text { 10. Compared to before I went through these experiences, my } \\
\text { religious/spiritual faith has strengthened. (R) }\end{array}$ & 7.62 & 3.04 \\
\hline Factor: Lack of forgiveness & 16.91 & 5.53 \\
\hline $\begin{array}{l}\text { 1. I feel betrayed by other health professionals whom I once trusted. } \\
\text { 7. I have forgiven myself for what's happened to me or to others whom }\end{array}$ & 4.92 & 3.18 \\
\hline I have cared for. (R) & 7.72 & 2.57 \\
\hline $\begin{array}{l}\text { 8. All in all, I am inclined to feel that I'm a failure in my work as a } \\
\text { health professional. }\end{array}$ & 2.31 & 2.24 \\
\hline $\begin{array}{l}\text { 9. I sometimes feel God is punishing me for what I've done or not done } \\
\text { while caring for patients. }\end{array}$ & 1.95 & 2.00 \\
\hline Total MISS-HP & 34.80 & 15.81 \\
\hline
\end{tabular}


Table 4

Comparison in PHQ-9 and GAD-7 scores regarding MISS-HP scores

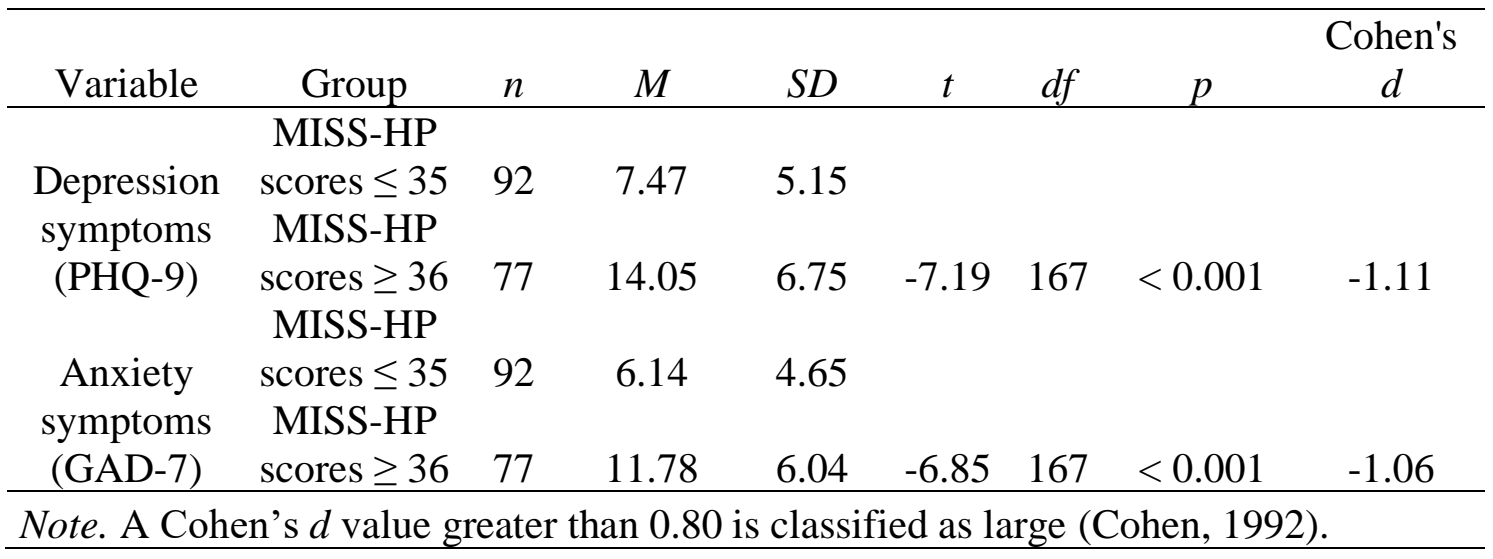


Table 5

Correlations between MISS-HP and LTS

\begin{tabular}{|c|c|c|c|c|c|c|}
\hline Variable & Statistic & $\begin{array}{l}\text { MISS-HP } \\
\text { Shame and } \\
\text { guilt }\end{array}$ & $\begin{array}{l}\text { MISS- } \\
\text { HP } \\
\text { Mistrust }\end{array}$ & $\begin{array}{l}\text { MISS-HP } \\
\text { Lack of } \\
\text { forgiveness }\end{array}$ & $\begin{array}{l}\text { LT-Faith } \\
\text { in } \\
\text { humanity }\end{array}$ & $\begin{array}{l}\text { LT- } \\
\text { Human } \\
\text { ism }\end{array}$ \\
\hline \multirow{5}{*}{$\begin{array}{c}\text { MISS-HP } \\
\text { Mistrust }\end{array}$} & $r$ & 0.22 & - & & & \\
\hline & $p$ & $<0.001$ & - & & & \\
\hline & Upper & & & & & \\
\hline & $95 \% \mathrm{CI}$ & 0.36 & - & & & \\
\hline & $\begin{array}{l}\text { Lower } \\
95 \% \text { CI }\end{array}$ & 0.07 & - & & & \\
\hline \multirow{4}{*}{$\begin{array}{l}\text { MISS-HP } \\
\text { Lack of } \\
\text { Forgiveness }\end{array}$} & $r$ & 0.47 & 0.06 & - & & \\
\hline & $p$ & $<0.001$ & 0.46 & - & & \\
\hline & $\begin{array}{l}\text { Upper } \\
95 \% \text { CI }\end{array}$ & 0.58 & 0.21 & - & & \\
\hline & $\begin{array}{l}\text { Lower } \\
95 \% \text { CI }\end{array}$ & 0.34 & -0.09 & - & & \\
\hline \multirow{4}{*}{$\begin{array}{c}\text { LT-Faith in } \\
\text { Humanity }\end{array}$} & $r$ & -0.12 & -0.33 & -0.23 & - & \\
\hline & $p$ & 0.13 & $<0.001$ & $<0.001$ & - & \\
\hline & $\begin{array}{c}\text { Upper } \\
95 \% \text { CI }\end{array}$ & 0.04 & -0.19 & -0.08 & - & \\
\hline & $\begin{array}{l}\text { Lower } \\
95 \% \text { CI }\end{array}$ & -0.26 & -0.46 & -0.37 & - & \\
\hline \multirow{4}{*}{$\begin{array}{c}\text { LT- } \\
\text { Humanism }\end{array}$} & $r$ & -0.02 & -0.17 & -0.11 & 0.50 & - \\
\hline & $p$ & 0.84 & 0.03 & 0.14 & $<0.001$ & - \\
\hline & $\begin{array}{c}\text { Upper } \\
95 \% \text { CI }\end{array}$ & 0.14 & -0.02 & 0.04 & 0.61 & - \\
\hline & $\begin{array}{l}\text { Lower } \\
95 \% \text { CI }\end{array}$ & -0.17 & -0.31 & -0.26 & 0.38 & - \\
\hline \multirow{4}{*}{$\begin{array}{c}\text { LT- } \\
\text { Kantianism }\end{array}$} & $r$ & 0.09 & -0.22 & 0.01 & 0.33 & 0.48 \\
\hline & $p$ & 0.24 & $<0.001$ & 0.85 & $<0.001$ & $<0.001$ \\
\hline & $\begin{array}{c}\text { Upper } \\
95 \% \text { CI }\end{array}$ & 0.24 & -0.07 & 0.17 & 0.46 & 0.59 \\
\hline & $\begin{array}{l}\text { Lower } \\
95 \% \text { CI }\end{array}$ & -0.06 & -0.36 & -0.14 & 0.19 & 0.35 \\
\hline \multicolumn{7}{|c|}{$\begin{array}{l}\text { Note. Correlation coefficients were determined by Pearson's } r \text {. Significant values } \\
(p<0.05) \text { are marked in bold. Descriptive statistics for the LTS are: Faith in Humanity } \\
(M=14.85, S D=2.88) \text {, Humanism }(M=17.40, S D=2.54) \text { and Kantianism }(M=16.55, \\
S D=2.71) .\end{array}$} \\
\hline
\end{tabular}


Table 6

Regression model explaining symptoms of depression

\begin{tabular}{|c|c|c|c|c|c|c|c|c|c|c|}
\hline \multirow[b]{2}{*}{ Model } & \multirow[b]{2}{*}{ Variables } & \multicolumn{2}{|c|}{$\begin{array}{c}\text { Non- } \\
\text { standardized }\end{array}$} & \multirow[t]{2}{*}{$\begin{array}{c}\text { Standardized } \\
\beta\end{array}$} & \multirow[t]{2}{*}{$t$} & \multirow[t]{2}{*}{$p$} & \multicolumn{2}{|c|}{$\begin{array}{l}95.0 \% \mathrm{CI} \\
\text { for } \beta\end{array}$} & \multicolumn{2}{|c|}{ Colineality } \\
\hline & & $\beta$ & $\mathrm{SE}$ & & & & LL & UL & Tolerance & VIF \\
\hline \multirow{5}{*}{1} & (Constant) & 10.43 & 1.23 & & 8.52 & 0.00 & 8.02 & 12.85 & & \\
\hline & Sex & 1.57 & 1.24 & 0.10 & 1.27 & 0.21 & -0.87 & 4.01 & 0.96 & 1.04 \\
\hline & Profession & -0.48 & 1.55 & -0.02 & -0.31 & 0.76 & -3.55 & 2.58 & 0.94 & 1.07 \\
\hline & $\begin{array}{l}\text { COVID-19 } \\
\text { diagnostic }\end{array}$ & -0.23 & 1.14 & -0.02 & -0.20 & 0.84 & -2.48 & 2.03 & 0.97 & 1.03 \\
\hline & $\begin{array}{l}\text { Experience } \\
\text { (years) }\end{array}$ & -0.12 & 0.05 & -0.18 & -2.34 & 0.02 & -0.22 & -0.02 & 0.97 & 1.03 \\
\hline \multirow{11}{*}{2} & (Constant) & -7.29 & 4.12 & & -1.77 & 0.08 & $\begin{array}{c}- \\
15.42\end{array}$ & 0.85 & & \\
\hline & Sex & -0.11 & 1.01 & -0.01 & -0.11 & 0.92 & -2.10 & 1.89 & 0.90 & 1.12 \\
\hline & $\begin{array}{l}\text { Profession } \\
\text { COVID-19 }\end{array}$ & 0.78 & 1.28 & 0.04 & 0.61 & 0.54 & -1.75 & 3.32 & 0.85 & 1.17 \\
\hline & diagnostic & -0.56 & 0.92 & -0.04 & -0.60 & 0.55 & -2.38 & 1.27 & 0.93 & 1.08 \\
\hline & $\begin{array}{l}\text { Experience } \\
\text { (years) } \\
\text { MISS-HP }\end{array}$ & -0.02 & 0.04 & -0.04 & -0.53 & 0.59 & -0.11 & 0.06 & 0.83 & 1.21 \\
\hline & $\begin{array}{l}\text { Shame and } \\
\text { guilt } \\
\text { MISS-HP }\end{array}$ & 0.18 & 0.06 & 0.21 & 2.91 & $<0.01$ & 0.06 & 0.29 & 0.69 & 1.45 \\
\hline & $\begin{array}{l}\text { Mistrust } \\
\text { MISS-HP }\end{array}$ & 0.30 & 0.08 & 0.26 & 3.82 & $<0.01$ & 0.14 & 0.45 & 0.78 & 1.28 \\
\hline & $\begin{array}{l}\text { Lack of } \\
\text { Forgiveness } \\
\text { LT-Faith in }\end{array}$ & 0.50 & 0.09 & 0.41 & 5.72 & $<0.01$ & 0.33 & 0.67 & 0.72 & 1.40 \\
\hline & $\begin{array}{l}\text { Humanity } \\
\text { LT- }\end{array}$ & -0.19 & 0.18 & -0.08 & -1.07 & 0.29 & -0.54 & 0.16 & 0.63 & 1.59 \\
\hline & $\begin{array}{l}\text { Humanism } \\
\text { LT- }\end{array}$ & 0.31 & 0.21 & 0.12 & 1.47 & 0.14 & -0.11 & 0.74 & 0.57 & 1.77 \\
\hline & Kantianism & 0.11 & 0.18 & 0.04 & 0.61 & 0.54 & -0.25 & 0.47 & 0.69 & 1.46 \\
\hline \multicolumn{11}{|c|}{$\begin{array}{l}\text { Note. Categorical data included the following values: sex }(0=\text { male, } 1=\text { female }) \text {, profession } \\
(0=\text { physician, } 1=\text { nurse }) \text {, previous COVID- } 19 \text { diagnostic }(0=\text { no, } 1=y e s) \text {. Significant values } \\
(p<0.05) \text { are marked in bold. }\end{array}$} \\
\hline
\end{tabular}


Table 7

Regression model explaining symptoms of anxiety

\begin{tabular}{|c|c|c|c|c|c|c|c|c|c|c|}
\hline \multirow[b]{2}{*}{ Model } & \multirow[b]{2}{*}{ Variables } & \multicolumn{2}{|c|}{ Non-standardized } & \multirow{2}{*}{$\begin{array}{c}\text { Standardized } \\
\beta\end{array}$} & \multirow[b]{2}{*}{$t$} & \multirow[b]{2}{*}{$p$} & \multicolumn{2}{|c|}{$\begin{array}{l}95.0 \% \text { CI } \\
\text { for } \beta\end{array}$} & \multicolumn{2}{|c|}{ Colineality } \\
\hline & & $\beta$ & $\mathrm{SE}$ & & & & $\mathrm{LL}$ & UL & Tolerance & VIF \\
\hline \multirow{5}{*}{1} & (Constant) & 7.73 & 1.08 & & 7.15 & 0.00 & 5.60 & 9.87 & & \\
\hline & Sex & 2.25 & 1.09 & 0.16 & 2.06 & 0.04 & 0.09 & 4.40 & 0.96 & 1.04 \\
\hline & Profession & -0.11 & 1.37 & -0.01 & 0.08 & 0.93 & -2.82 & 2.59 & 0.94 & 1.07 \\
\hline & $\begin{array}{l}\text { COVID-19 } \\
\text { diagnostic }\end{array}$ & 0.51 & 1.01 & 0.04 & 0.51 & 0.61 & -1.48 & 2.50 & 0.97 & 1.03 \\
\hline & $\begin{array}{l}\text { Experience } \\
\text { (years) }\end{array}$ & -0.10 & 0.04 & -0.17 & 2.24 & 0.03 & -0.19 & -0.01 & 0.97 & 1.03 \\
\hline \multirow{19}{*}{2} & & & & & - & & - & & & \\
\hline & (Constant) & -5.54 & 3.80 & & 1.46 & 0.15 & 13.04 & 1.96 & & \\
\hline & Sex & 0.85 & 0.93 & 0.06 & 0.91 & 0.36 & -0.99 & 2.69 & 0.90 & 1.12 \\
\hline & Profession & 0.58 & 1.18 & 0.03 & 0.49 & 0.62 & -1.76 & 2.92 & 0.85 & 1.17 \\
\hline & COVID-19 & & & & & & & & & \\
\hline & diagnostic & 0.26 & 0.85 & 0.02 & 0.31 & 0.76 & -1.42 & 1.95 & 0.93 & 1.08 \\
\hline & Experience & & & & - & & & & & \\
\hline & (years) & -0.02 & 0.04 & -0.04 & 0.57 & 0.57 & -0.10 & 0.06 & 0.83 & 1.21 \\
\hline & MISS-HP & & & & & & & & & \\
\hline & $\begin{array}{l}\text { Shame and } \\
\text { guilt } \\
\text { MISS-HP }\end{array}$ & 0.12 & 0.06 & 0.16 & 2.10 & 0.04 & 0.01 & 0.23 & 0.69 & 1.45 \\
\hline & Mistrust & 0.19 & 0.07 & 0.19 & 2.61 & 0.01 & 0.05 & 0.33 & 0.78 & 1.28 \\
\hline & MISS-HP & & & & & & & & & \\
\hline & $\begin{array}{l}\text { Lack of } \\
\text { Forgiveness }\end{array}$ & 0.47 & 0.08 & 0.43 & 5.80 & 0.00 & 0.31 & 0.63 & 0.72 & 1.40 \\
\hline & LT-Faith in & & & & & & & & & \\
\hline & Humanity & -0.20 & 0.16 & -0.10 & 1.22 & 0.23 & -0.53 & 0.12 & 0.63 & 1.59 \\
\hline & LT- & & & & & & & & & \\
\hline & Humanism & 0.40 & 0.20 & 0.17 & 2.02 & 0.04 & 0.01 & 0.79 & 0.57 & 1.77 \\
\hline & LT- & & & & - & & & & & \\
\hline & Kantianism & -0.09 & 0.17 & -0.04 & 0.56 & 0.58 & -0.42 & 0.24 & 0.69 & 1.46 \\
\hline
\end{tabular}

